\title{
Association of human $\beta$-herpesviruses with the development of cervical cancer: bystanders or cofactors
}

\author{
P K S Chan, M Y M Chan, W W H Li, D P C Chan, J L K Cheung, A F Cheng
}

\begin{abstract}
BackgroundlAim-Human papillomaviruses (HPVs) are important, but not sufficient, for the development of cervical cancer. All three human $\beta$-herpesviruses-cytomegalovirus (CMV) and human herpesviruses (HHV) types 6 and 7-have been detected in the cervix. In addition, CMV and HHV-6 can interact with HPVs in vivo. This study examined the possible role of $\beta$-herpesviruses in cervical cancer development.

Methods-HPV, CMV, HHV-6, and HHV-7 were detected by the polymerase chain reaction using cervical scrapes taken at colposcopy from 388 women. HPV types were identified using restriction fragment length polymorphisms. Colposcopy guided biopsies were taken from abnormal areas, and the histological findings were regarded as the final diagnoses. The associations between herpesvirus infection and the degree of cervical lesion were analysed with respect to HPV status.
\end{abstract}

Results-Of the 388 women, $51.8 \%$ had a normal cervix, $14.4 \%$ had cervical intraepithelial neoplasia grade 1 (CIN1), 8.2\% had CIN2, $19.3 \%$ had CIN3, and $6.2 \%$ had invasive carcinoma. Overall, the positive rates for high, intermediate, and low risk HPVs were $18.8 \%, 21.4 \%$, and $5.2 \%$, respectively. Fifteen patients harboured HPVs for which the genotype could not be identified. Positive rates for CMV, HHV-6, and HHV-7 were $9.5 \%, 3.6 \%$, and $3.4 \%$, respectively. HPV positive patients carried a higher risk for high grade lesions (CIN2/3 or carcinoma) (odds ratio (OR), $5.24 ; 95 \%$ confidence interval (CI), 3.19 to 8.62; $\left.\chi^{2}=51.79 ; p<0.001\right)$, whereas those positive for CMV, HHV-6, or HHV-7 did not. Thirteen of 131 patients with high grade lesions had HPV/herpesvirus coinfections, but no association with the cervical lesion was noted. Furthermore, positive rates for herpesviruses among HPV negative, high/intermediate risk HPV negative, and high risk HPV negative subgroups were similarly low and without a significant association.

Conclusions-The ubiquitous nature of herpesviruses may pose difficulty in elucidating their pathogenic role. These results indicate that CMV, HHV-6, and HHV-7 are bystanders rather than cofactors in the oncogenesis of cervical cancer.

(f Clin Pathol 2001;54:48-53)
Keywords: human papillomavirus; human herpesvirus 6; human herpesvirus 7

Human papillomaviruses (HPVs) are important, but not sufficient to cause cervical cancer. ${ }^{12}$ Recently, the search for cofactors involved in the multistep oncogenic pathway has received much interest. Sexually transmitted agents, particularly viral infections, have been postulated to have a synergistic role in the carcinogenesis of cervical neoplasia..$^{3-5}$ Apart from herpes simplex virus, which has long been suspected to act as an "initiator" in the development of cervical cancer, ${ }^{3}$ other herpesviruses are also potential candidates. The immediate-early gene products of cytomegalovirus (CMV) can transactivate other viral and cellular genes, ${ }^{67}$ and it has been suggested that concurrent genital infection with CMV and HPV might increase the risk for cervical cancer. ${ }^{8}$ A putative oncogene has been found in the human herpesvirus 6 (HHV-6) genome, ${ }^{9-11}$ and molecular clones of HHV-6 that can transactivate papillomavirus have been reported. ${ }^{12}$ In addition, the presence of CMV and HHV-6 in the cervix of a considerable proportion of women with normal and abnormal cytologies $^{13}{ }^{14}$ gives them an opportunity to interact with genital HPVs.

CMV, HHV-6, and HHV-7 share a high degree of genomic homology and are classified under the same subfamily of the $\beta$-herpesvirinae. ${ }^{15}$ Thus, these herpesviruses might share a similar oncogenic potential. Although all these viruses are ubiquitous and have been detected in the cervix, ${ }^{16}{ }^{17}$ epidemiological data regarding their association with genital HPVs and their role in cervical cancer have not reached a consensus. Here, we examined the presence of these $\beta$-herpesviruses and HPVs in a series of Chinese women with various cervical lesions to elucidate their role in the development of cervical cancer.

\section{Methods}

STUDY POPULATION

A total of 388 Chinese women referred to the colposcopy clinic at Queen Elizabeth Hospital, Hong Kong, for the management of abnormal cervical cytologies were recruited with written informed consent. In Hong Kong, cervical cancer ranks fourth for new cancers and seventh for deaths from cancer in women. The median age at diagnosis is 56 years with an age standardised rate of $12.7 / 100000 .^{18}$ 
CLASSIFICATION OF CERVICAL LESIONS

All recruited women were examined by colposcopy with biopsies taken from abnormal areas and followed by local surgical treatment if necessary. All histological assessments were performed by an experienced pathologist. The classification of cervical lesions was based on histological findings according to the World Health Organisation's classification. ${ }^{19}$ When there were discrepancies between the histological findings of colposcopic biopsies and excised tissues, the worst results were regarded as the final diagnoses. Women with normal colposcopy/biopsy had follow up cytology performed at three to six month intervals. For the purpose of our study, women with normal colposcopy/biopsy who had normal cytology results throughout the subsequent 12 month follow up period were classified as normal. The virology results were unknown to clinicians and the pathologist throughout the entire follow up. The study protocol was approved by the local institution ethics committee.

\section{VIRAL DNA DETECTION}

A cervical scrape sample was obtained from each woman at the time of colposcopy. Total DNA was extracted by a previously described method. $^{20}$ The quality of the DNA was assessed by the polymerase chain reaction (PCR) targeting the $358 \mathrm{bp}$ fragment of the human $\beta$-globin gene. ${ }^{21}$ The presence of $\mathrm{CMV}$, HHV-6, and HHV-7 DNA was detected by nested PCR. The primer sets used have been shown to be specific and do not cross amplify other herpesviruses (table 1). ${ }^{22-25}$ Briefly, $5 \mu l$ of the extracted DNA was amplified in a $50 \mu \mathrm{l}$ reaction mixture containing PCR buffer (10 mM Tris/ $\mathrm{HCl}$ (pH 8.3), $50 \mathrm{mM} \mathrm{KCl}$, and $1.5 \mathrm{mM} \mathrm{MgCl}$ ), $200 \mu \mathrm{M}$ of each dNTP, 1 unit of Taq polymerase (Pharmacia Biotech, Uppsaala, Sweden), and $0.25 \mu \mathrm{M}$ of each primer. An initial denaturation at $94^{\circ} \mathrm{C}$ for four minutes was followed by 30 cycles of one minute each for denaturation $\left(94^{\circ} \mathrm{C}\right)$, annealing $\left(55^{\circ} \mathrm{C}\right)$, and extension $\left(72^{\circ} \mathrm{C}\right)$, with an eight minute additional extension step at $72^{\circ} \mathrm{C}$ after the last cycle. An aliquot of $2 \mu \mathrm{l}$ of the first round PCR product was amplified in a second round PCR using the same conditions with the omission of the initial denaturation step.
For the detection of HPV DNA, a single round PCR based on the degenerate primers MY09 and MY11 was used (table 1). ${ }^{26}$ These primers are capable of amplifying at least 40 genital HPV types. ${ }^{27}{ }^{28}$ The amplification conditions were the same, except that the reaction was run for 40 cycles. HPV types were further characterised by restriction fragment length polymorphism using endonucleases RsaI and DdeI, as described previously. ${ }^{28} 29$

The detection limit of PCR was estimated by limiting dilution using plasmids containing the target sequences of CMV, HHV-6, HHV-7, and HPV types $6,11,16$, and 18 , respectively. The nested PCRs for CMV, HHV-6, and $\mathrm{HHV}-7$ had a sensitivity equivalent to five to 10 genome copies of template, whereas the detection limit for HPV PCR was 100 genome copies.

To avoid possible cross contamination, all PCR reactions were carried out under stringent conditions following the recommendations of Kwok and Higuchi. ${ }^{30}$ A negative control was included after each fifth sample. In addition, all positive samples were repeated in a separate PCR run and were all reproducible.

\section{STATISTICAL ANALYSIS}

The age distribution of different patient groups was compared by independent samples $t$ test. Associations between viral DNA positivity and the degree of cervical lesion were assessed by calculating the odds ratios (OR) and $95 \%$ confidence intervals (CI). The $\chi^{2}$ test or Fisher's exact test was used as appropriate to compare categorical variables. Two tailed $\mathrm{p}$ values of $<0.05$ were regarded as significant.

\section{Results}

The 388 recruited Chinese women were aged between 16 and 88 years (mean, 40.4; SD, 11.4). Two hundred and one patients $(51.8 \%)$ had a normal cervix, $56(14.4 \%)$ had biopsy confirmed cervical intraepithelial neoplasia grade 1 (CIN1), 32 (8.2\%) had biopsy confirmed CIN2, 75 (19.3\%) had biopsy confirmed CIN3, and $24(6.2 \%)$ had invasive cervical carcinoma (two patients with invasive adenocarcinoma, others had invasive squamous cell carcinoma).

Table 1 Primers used for the polymerase chain reaction

\begin{tabular}{|c|c|c|c|c|}
\hline Target DNA & & Primer & $\begin{array}{l}\text { Amplicon } \\
(b p)\end{array}$ & Ref. \\
\hline \multirow[t]{2}{*}{$\begin{array}{l}\text { CMV morphological } \\
\text { transforming region II }\end{array}$} & Outer & $\begin{array}{l}\text { CMTR1: 5'-CTG TCG GTG ATG GTG TCT TC-3'; } \\
\text { CMTR2: 5'-CCC GAC ACG CGG AAA AGA AA-3' }\end{array}$ & 230 & \multirow[t]{2}{*}{22} \\
\hline & Inner & $\begin{array}{l}\text { CMTR3: 5'-TCT CTG GTC CTG ATC GTC TT-3'; } \\
\text { CMTR4: 5'-GTG ACC TAC CAA CGT AGG TT-3' }\end{array}$ & 168 & \\
\hline \multirow[t]{2}{*}{$\begin{array}{l}\text { HHV- } 6 \text { major capsid } \\
\text { protein encoding region }\end{array}$} & Outer & $\begin{array}{l}\text { H6-6: 5'-AAG CTT GCA CAA TGC CAA AAA ACA G-3'; } \\
\text { H6-7: 5'-CTC GAG TAT GCC GAG ACC CCT AAT C-3' }\end{array}$ & 223 & \multirow[t]{2}{*}{23} \\
\hline & Inner & $\begin{array}{l}\text { NH-6: 5'-TCC ATT ATT TTG GCC GCA TTC GT-3'; } \\
\text { NH-7: 5'-TGT TAG GAT ATA CCG ATG TGC GT-3' }\end{array}$ & 130 & \\
\hline \multirow[t]{2}{*}{ HHV-7 U10 region } & Outer & $\begin{array}{l}\text { P1: 5'-TAT CCC AGC TGT TTT CAT ATA GTA AC-3'; } \\
\text { P2: 5'-GCC TTG CGG TAG CAC TAG ATT TTT TG-3' }\end{array}$ & 186 & \multirow[t]{2}{*}{25} \\
\hline & Inner & $\begin{array}{l}\text { P3: 5'-CAG AAA TGA TAG ACA GAT GTT GG-3'; } \\
\text { P4: 5'-TAG ATT TTT TGA AAA AGA TTT AAT AAC-3' }\end{array}$ & 124 & \\
\hline HPV L1 ORF & & $\begin{array}{l}\text { MY09: 5'-CGT CCM ARR GGA WAC TGA TC-3' } \\
\text { MY11: 5'-GCM CAG GGW CAT AAY AAT GG-3' } \\
(\mathrm{M}=\mathrm{A} \text { or } \mathrm{C} ; \mathrm{R}=\mathrm{A} \text { or } \mathrm{G} ; \mathrm{W}=\mathrm{A} \text { or } \mathrm{T} ; \mathrm{Y}=\mathrm{C} \text { or } \mathrm{T})\end{array}$ & 450 & 26 \\
\hline
\end{tabular}

CMV, cytomegalovirus; HHV, human herpesvirus; HPV, human papillomavirus; ORF, open reading frame. 


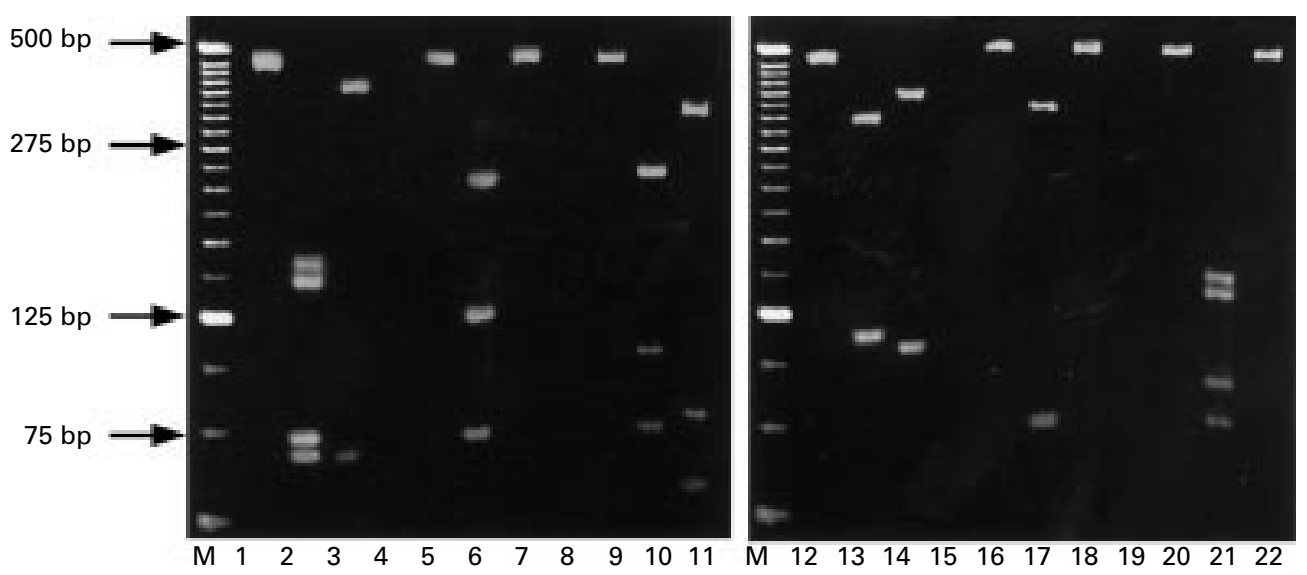

Figure 1 Restriction fragment length patterns of representative human papillomavirus (HPV) genotypes obtained by endonuclease digestion of $L 1$ open reading frame (ORF) PCR products. Lane M: 25 bp ladder marker. Lanes 1-3: HPV6 not restricted, restricted with RsaI, and restricted with DdeI, respectively. Lane 4: blank. Lanes 5-7: HPV11 not restricted, restricted with RsaI, and restricted with DdeI, respectively. Lane 8: blank. Lanes 9-11: HPV33 not restricted, restricted with RsaI, and restricted with DdeI, respectively. Lanes 12-14: HPV58 not restricted, restricted with RsaI, and restricted with DdeI, respectively. Lane 15: blank. Lanes 16-18: HPV16 not restricted, restricted with RsaI, and restricted with DdeI, respectively. Lane 19: blank. Lanes 20-22: HPV18 not restricted, restricted with RsaI, and restricted with DdeI, respectively.

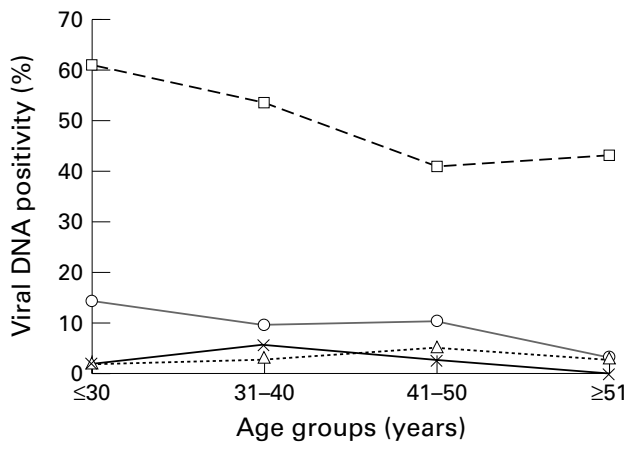

Figure 2 Prevalence of human papillomavirus (HPV), cytomegalovirus (CMV), human herpesvirus 6 (HHV-6), and HHV-7 in the cervix of 388 women with abnormal cervical cytologies by age groups. Numbers of patients tested in each age group: $\leqslant 30$ years, 56 patients; $31-40$ years, 159 patients; $41-50$ years, 115 patients; $>51$ years, 58 patients. Squares, HPV; circles, CMV; triangles, HHV-6; crosses, HHV-7.

Overall, 191 of the 388 cervical samples $(49.2 \%)$ were positive for HPV DNA. All the remaining $197 \mathrm{HPV}$ negative samples were positive in the $\beta$-globin PCR, indicating that an adequate preparation had been obtained. Seventy three $(38.2 \%)$ of the $191 \mathrm{HPV}$ positive women harboured high risk HPV types (HPV types 16/18), 83 (43.5\%) harboured intermediate risk types (HPV types $31,33,35,52,58$ ), $20(10.5 \%)$ carried low risk types (HPV types 6/11), and the remaining $15(7.9 \%)$ had HPVs in which the genotypes could not be identified based on their restriction patterns. Figure 1 shows the restriction patterns of representative HPV types. Twenty patients had coinfection with two types of HPVs, and they were classified according the HPV type that was associated with a higher risk. The positive rates for CMV, HHV-6, and HHV-7 were 9.5\%, $3.6 \%$, and $3.4 \%$, respectively. Members of the HPV positive group were significantly younger than those without HPV infection (mean age, $39.2 v 41.5$ years; $\mathrm{p}<0.05$ by $t$ test). In contrast, women positive for CMV, HHV-6, or HHV-7 had no significant difference in age distribution (fig 2).

Table 2 shows the distribution of viral DNA positive samples among various degrees of cervical lesion. When the viral DNA positive rates between patients with normal/low grade cervical lesions (a normal cervix or CIN1) and those with high grade cervical lesions (CIN2/3 or carcinoma) were compared, the presence of HPVs carried an increased risk for high grade cervical lesions (OR, 5.24; 95\% CI, 3.19 to 8.62; $\left.\chi^{2}=51.79 ; \mathrm{p}<0.001\right)$. In contrast, the presence of CMV, HHV-6, or HHV-7 did not significantly increase the risk for high grade cervical lesions (CMV: OR, 0.81; 95\% CI, 0.36 to $1.79 ; \chi^{2}=0.3 ; \mathrm{p}=0.585$. HHV-6: OR, 1.09 ; $95 \%$ CI, 0.31 to $3.66 ; p=1.0$ by Fisher's exact

Table 2 Prevalence of HPV, CMV, HHV-6, and HHV-7 DNA in the cervix of 388 women according to the degree of cervical lesion

\begin{tabular}{lccccccc}
\hline \multicolumn{7}{c}{ No. (\%) of women positive for the indicated viral DNAt } \\
\cline { 3 - 8 } Cervical lesion & No. tested & High risk HPV & $\begin{array}{l}\text { Intermediate } \\
\text { risk HPV }\end{array}$ & Low risk HPV & CMV & HHV-6 & $H H V-7$ \\
\hline Normal/inflamed & 201 & $10(5.0)$ & $24(11.9)$ & $14(7.0)$ & $17(8.5)$ & $7(3.5)$ & $7(3.5)$ \\
CIN1 & 56 & $16(28.6)$ & $19(33.9)$ & $2(3.6)$ & $9(16.1)$ & $2(3.6)$ & $2(3.6)$ \\
CIN2 & 32 & $6(18.8)$ & $8(25.0)$ & 0 & $3(9.4)$ & 0 & 0 \\
CIN3 & 75 & $28(37.3)$ & $24(32.0)$ & $4(5.3)$ & $8(10.7)$ & $3(4.0)$ & $3(4.0)$ \\
Carcinoma & 24 & $13(54.2)$ & $8(33.3)$ & 0 & 0 & $2(8.3)$ & $1(4.2)$ \\
Total & 388 & $73(18.8)$ & $83(21.4)$ & $20(5.2)$ & $37(9.5)$ & $14(3.6)$ & $13(3.4)$ \\
\hline
\end{tabular}

†15 women had HPVs for which the genotype could not be identified.

$\mathrm{CIN}$, cervical intraepithelial neoplasia grade; CMV, cytomegalovirus; HHV, human herpesvirus; HPV, human papillomavirus. 
Table 3 Prevalence of coinfection with HPV and herpesviruses in the cervix of 388 women according to the degree of cervical lesion

\begin{tabular}{lclll}
\hline & \multicolumn{4}{c}{$\begin{array}{l}\text { No. (\%) of women with coinfection of } \\
\text { HPV and the indicated virus }\end{array}$} \\
\cline { 3 - 5 } \begin{tabular}{l} 
Cervical lesion \\
\cline { 3 - 5 }
\end{tabular} & $\begin{array}{l}\text { No. } \\
\text { tested }\end{array}$ & $C M V$ & HHV-6 & HHV-7 \\
\hline $\begin{array}{l}\text { Normal/ } \\
\text { inflamed }\end{array}$ & 201 & $8(4.0)$ & $2(1.0)$ & $2(1.0)$ \\
CIN1 & 56 & $6(10.7) \dagger$ & $2(3.6) \ddagger$ & $1(1.8)$ \\
CIN2 & 32 & $1(3.1)$ & 0 & 0 \\
CIN3 & 75 & $7(9.3) \ddagger$ & $2(2.7)$ & $3(4.0)$ \\
Carcinoma & 24 & 0 & 0 & $1(4.2)$ \\
Total & 388 & $22(5.7)$ & $6(1.5)$ & $7(1.8)$ \\
\hline
\end{tabular}

†One woman coinfected with HHV-6.

‡One woman coinfected with HHV-7.

CIN, cervical intraepithelial neoplasia grade; CMV, cytomegalovirus; HHV, human herpesvirus; HPV, human papillomavirus.

test. HHV-7: OR, 0.87; 95\% CI, 0.22 to 3.16 ; $\mathrm{p}=1.0$ by Fisher's exact test).

PATIENTS COINFECTED WITH TWO TYPES OF HERPESVIRUSES

Four patients (aged 23, 31, 40, and 45 years) were coinfected with two types of herpesviruses. One was positive for CMV, $\mathrm{HHV}-7$, and an intermediate risk HPV and had a CIN3 lesion. The other two patients had CIN1 lesions; one was positive for $\mathrm{HHV}-6, \mathrm{HHV}-7$, and an intermediate risk HPV, and the other was positive for CMV, HHV-6, and a low risk HPV. The remaining patient had a normal cervix and was coinfected with CMV and HHV-6, but negative for HPV. None of the studied women had coinfection with more than two types of herpesviruses.

PATIENTS COINFECTED WITH HPV AND HERPESVIRUS

Thirty two women had HPV and herpesvirus coinfection, $13(40.6 \%)$ of whom had high grade cervical lesions (CIN2/3 or carcinoma). Table 3 shows the status of viral infection with respect to the degree of cervical lesion. Coinfection of HPV with one or more herpesvirus did not carry a significant increase in the risk for a high grade cervical lesion (OR, 1.38; $95 \% \mathrm{CI}, 0.062$ to $\left.3.05 ; \chi^{2}=0.73 ; \mathrm{p}=0.391\right)$. In addition, when subgroup analyses were performed for coinfections of HPV with each of the herpesviruses no significant increase in risk was seen (HPV and CMV: OR, 1.13; 95\% CI, 0.42 to $2.97 ; \chi^{2}=0.07 ; \mathrm{p}=0.791$. HPV and HHV-6: OR, 0.98; 95\% CI, 0.12 to 6.31 ; $\mathrm{p}=1.0$ by Fisher's exact test. HPV and HHV-7: OR, 2.67; 95\% CI, 0.5 to 15.24; $\mathrm{p}=0.232$ by Fisher's exact test).

PATIENTS NEGATIVE FOR HIGH RISK HPV TYPES In total, 315 patients were negative for high risk HPVs (types 16/18). The positive rates for CMV, HHV-6, and HHV-7 in this subgroup were $8.9 \%, 3.8 \%$, and $3.8 \%$, respectively. Of these 315 patients, 84 had high grade lesions (CIN2/3 or carcinoma) with seven (8.3\%), three $(3.6 \%)$, and two $(2.1 \%)$ positive for CMV, HHV-6, and $\mathrm{HHV}-7$, respectively. In this subgroup who were negative for high risk HPVs, herpesvirus infection did not carry a significant increase in risk for high grade cervical lesions (CMV: OR, 0.91; 95\% CI, 0.34 to
$2.37 ; \chi^{2}=0.04 ; \mathrm{p}=0.835$. HHV-6: OR, 0.74; $95 \%$ CI, 0.16 to $2.96 ; \mathrm{p}=0.767$ by Fisher's exact test. HHV-7: OR, 0.49; 95\% CI, 0.07 to $2.40 ; \mathrm{p}=0.525$ by Fisher's exact test).

PATIENTS NEGATIVE FOR HIGH/INTERMEDIATE RISK HPV TYPES

Among the 232 patients who were negative for high or intermediate risk HPVs, the positive rates for $\mathrm{CMV}, \mathrm{HHV}-6$, and $\mathrm{HHV}-7$ were $8.6 \%, 3.9 \%$, and $3.0 \%$, respectively. Of these 232 patients, 44 had high grade lesions (CIN2/3 or carcinoma), with four ( $9 \%$ ), three $(6.8 \%)$, and none positive for CMV, HHV-6, and HHV-7, respectively. No significant association between herpesvirus infection and high grade cervical lesion was observed (CMV: OR, $1.08 ; 95 \%$ CI, 0.29 to $3.69 ; \mathrm{p}=1.0$ by Fisher's exact test. HHV-6: OR, $2.22 ; 95 \%$ CI, 0.42 to $10.57 ; \mathrm{p}=0.377$ by Fisher's exact test. HHV-7: OR, $0.00 ; 95 \%$ CI, 0.00 to 3.37 ; $\mathrm{p}=0.352$ by Fisher's exact test).

PATIENTS NEGATIVE FOR ALL HPV TYPES

Among the 197 patients who were negative for HPV DNA, 14 (7.1\%) were positive for CMV alone, seven $(3.6 \%)$ were positive for HHV-6 alone, six $(3.0 \%)$ were positive for HHV-7 alone, and one $(0.5 \%)$ was coinfected with CMV and HHV-6. Most of these HPV negative but herpesvirus positive patients had a normal cervix or low grade cervical lesions; only two patients had CIN2 (both infected with CMV), two patients had CIN3 (one infected with CMV, the other infected with HHV-6), and two other patients had invasive carcinoma (both were infected with HHV-6).

\section{Discussion}

The involvement of cocarcinogens in HPV related oncogenesis is supported by observations that the UV part of sunlight is necessary in the development of epidermodysplasia verruciformis, ${ }^{31} x$ rays are necessary in laryngeal papillomatosis, ${ }^{32}$ and carcinogens containing bracken fern are necessary in oesophageal papillomatosis of cattle. ${ }^{33}$ As for cervical cancer in humans, nicotine, ${ }^{34}$ oral contraceptives, ${ }^{35}$ dietary variables, ${ }^{36}$ and coinfections with other sexually transmitted agents have all been suggested as potential cocarcinogens, ${ }^{3}$ but conclusive evidence has yet to be produced.

In our study, the quality of the extracted DNA preparation was assessed by PCR targeting the $\beta$-globin gene. Although the amplified $\beta$-globin sequence is approximately $100 \mathrm{bp}$ shorter than the target of HPV PCR, given that the original samples were cervical scrapes, it is likely that the $\beta$-globin positive results indicated an adequate preparation for HPV PCR.

Our results show that infection with HPVs, as expected, was associated with an increased risk for high grade cervical lesion. However, all the three $\beta$-herpesviruses examined were present at low frequencies and did not carry a significant increase in risk for high grade cervical lesions. Among the 24 patients with invasive carcinoma, only two were infected with HHV-6, one with HHV-7, and none with CMV. Although both HHV-6 positive patients 
who had invasive carcinoma were negative for HPV, the overall picture does not suggest a causal association. Because a marginal effect of herpesviruses could be masked by the presence of high/intermediate risk HPV-type infections, we analysed the positive rates of herpesviruses among the high risk HPV negative, high/ intermediate risk HPV negative, and HPV negative and HPV/herpesvirus coinfected subgroups with respect to the degree of cervical lesion, but still found no positive evidence.

It has been shown in vitro that CMV can enhance the transforming ability of bovine papillomavirus, ${ }^{37}$ and HHV- 6 can enhance the expression of HPV oncoproteins E6 and E7. ${ }^{12}$ If these mechanisms are relevant in the development of cervical cancer, the ability of these herpesviruses to persist in cervical epithelial cells might be crucial. However, the available epidemiological data are conflicting. Reports of detecting CMV in cervical cancer, using similar highly sensitive PCRs, have not reached a consensus. Han et al reported the presence of CMV in $67 \%$ of Taiwanese patients with cervical cancer. ${ }^{38}$ In contrast, Thompson et al found that only $4 \%$ of Australian women with cervical cancer were positive for CMV. ${ }^{39}$ Findings on HHV-6 are also inconclusive. Yadav et al detected HHV-6 sequences in 10 of 26 cervical carcinoma tissues by in situ hybridisation..$^{40}$ Wang et al found two of eight cervical carcinoma specimens positive for HHV- 6 by PCR. ${ }^{41}$ On the other hand, Romano et al reported that only one of 85 women with abnormal cervical cytology was positive for HHV-6, and in that series none of the six patients with invasive carcinoma had HHV-6 detected by PCR. ${ }^{14}$ As for HHV-7, although it has been detected in the uterine cervix, ${ }^{16}$ investigations on its association with cervical cancer are lacking.

Attempts to elucidate the pathogenic role of herpesviruses in human diseases are often complicated by the fact that they are ubiquitous. Our results, in contrast to those of others, ${ }^{38} 4041$ suggest that CMV, HHV-6, and HHV-7 are bystanders rather than cofactors in the development of cervical cancer. Nonetheless, the approach that we used cannot localise morphologically the viruses identified, and thus cannot determine whether the herpesviruses and HPVs were present within the same cells. According to previous in vitro observations, ${ }^{6712}$ such coexistance within the same cell is essential for herpesviruses to have an effect on the expression of HPV oncoproteins. Furthermore, the possibility that these herpesviruses adopt a "hit and run strategy" after their transformation of host cells cannot be excluded. Such mechanisms can only be proved by prospective studies comparing the incidences of cervical cancer between cohorts with and without coinfections of HPV and the potential candidate viruses.

The study was supported by the UGC Direct Grant 2040622 from The Chinese University of Hong Kong.

1 Herrington CS. Human papillomaviruses and cervical neoplasia. I. Classification, virology, pathology, and epidemiology. $\mathcal{F}$ Clin Pathol 1994;47:1066-72.
2 Herrington CS. Human papillomaviruses and cervical neoplasia. II. Interaction of HPV with other factors. F Clin plasia. II. Interaction

3 Zur Hausen H. Human genital cancer: synergism between two virus infections or synergism between a virus infection and initiating events? Lancet 1982;2:1370-2.

4 Schmauz R, Okong P, De Villiers EM, et al. Multiple infections in cases of cervical cancer from a high-incidence area in tropical Africa. Int 7 Cancer 1989;43:805-9.

5 Kjaer SK, De Villiers EM, Caglayan H, et al. Human papillomavirus, herpes simplex virus and other potential risk factors for cervical cancer in a high-risk area (Greenland) and a low-risk area (Denmark) - a second look. Brf Cancer 1993;67:830-7

6 Boldogh I, Abubakar S, Deng CZ, et al. Transcriptional activation of cellular oncogenes fos, jun, and myb by human cytomegalovirus. F Virol 1991;65:1568-71.

7 Colberg-Poley AM, Santomenna LD, Benfield PA, et al. Interactions between human cytomegalovirus immediateearly genes in transactivation of viral and cellular promoters. In: MP Landini, ed. Progress in cytomegalovirus research. Amsterdam: Elsevier Science Publishers, 1991: 256-62.

8 Shen CY, Ho MS, Chang SF, et al. High rate of concurrent genital infections with human cytomegalovirus and human papillomaviruses in cervical cancer patients. F Infect Dis 1993;168:449-52.

9 Pellett PE, Black JB, Yamamoto M. Human herpesvirus 6: the virus and the search for its role as a human pathogen. Adv Virus Res 1992;41:1-52.

10 Razzaque A, Williams O, Wang J, et al. Neoplastic transformation of immortalized human epidermal keratinocytes by two HHV-6 DNA clones. Virology 1993;195:113-20.

11 Thompson J, Choudhury S, Kashanchi F, et al. A transforming fragment within the direct repeat region of human herpesvirus type 6 that transactivates HIV-1. Oncogene 1994;9:1167-75.

12 Chen M, Popescu N, Woodworth C, et al. Human herpesvirus 6 infects cervical epithelial cells and transactivates human papillomavirus gene expression. F Virol 1994;68: human $1173-8$.

13 Koffa M, Koumantakis E, Ergazaki M, et al. Association of herpesvirus infection with the development of genital cancer. Int $\mathcal{F}$ Cancer 1995;63:58-62.

14 Romano N, Romano FM, Viviano E, et al. Rare association of human herpesvirus 6 DNA with human papillomavirus DNA in cervical smears of women with normal and abnormal cytologies. F Clin Microbiol 1996;34:1589-91.

15 Berneman ZN, Ablashi DV, Li G, et al. Human herpesvirus 7 is a T-lymphotropic virus and is related to, but significantly different from, human herpesvirus 6 and human cytomegalovirus. Proc Natl Acad Sci USA 1992;89:10552-6.

16 Okuno T, Oishi H, Hayashi K, et al. Human herpesviruses 6 and 7 in cervices of pregnant women. 7 Clin Microbiol 1995;33:1968-70

17 Gradilone A, Vercillo R, Napolitano M, et al. Prevalence of human papillomavirus, cytomegalovirus, and Epstein-Barr virus in the cervix of healthy women. $f$ Med Virol 1996;50: $1-4$.

18 Hong Kong Cancer Registry. Cancer incidence and mortality in Hong Kong. Hong Kong: Hospital Authority, 1996:20.

19 Scully RE, Bonfiglio TA, Kurman RJ, et al. Histological typing of female genital tract tumours. In: World Health Organing of female genital tract tumours. In: World Health Organed. Berlin: Springer-Verlag, 1994:39-54.

20 Shibata D. PCR-based detection of the herpesviruses and the human papillomaviruses. In: Ehrlich GD, Greenberg $\mathrm{SJ}$, eds. PCR-based diagnostics in infectious disease. Massachusetts: Blackwell Scientific Publications, 1994: $475-6$.

21 Lo YMD, Mehal WZ, Fleming KA. In vitro amplification of hepatitis B virus sequences from liver tumour DNA and from paraffin wax embedded tissues using the polymerase chain reaction. $\mathcal{F}$ Clin Pathol 1989;42:840-6.

22 Khan G, Kangro HO, Coates PJ, et al. Inhibitory effects of urine on the polymerase chain reaction for cytomegalovirus DNine on the polymerase chain reaction Pathol 1991;44:360-5.

23 Gopal MR, Thomson BJ, Fox J, et al. Detection by PCR of HHV-6 and EBV DNA in blood and oropharynx of healthy adults and HIV-seropositives. Lancet 1990;335:1598-9.

24 Wang FZ, Dahl H, Linde A, et al. Lymphotropic herpesviruses in allogeneic bone marrow transplantation. Blood 1996;88:3615-20.

25 Sada E, Yasukawa M, Ito C, et al. Detection of human herpesvirus 6 and human herpesvirus 7 in the submandibular gland, parotid gland, and lip salivary gland by PCR. f Clin Microbiol 1996;34:2320-1.

26 Ting Y, Manos MM. Detection and typing of genital human papillomavirus. In: Innis MA, Gelfond DH, Sninsky JJ, et al, eds. PCR protocol: a guide to methods and applications. San Diego: Academic Press, 1990:356-67.

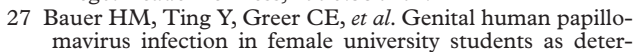
mined by a PCR-based method. F Am Med Assoc 1991;265: $472-7$.

28 Bernard HU, Chan SY, Manos MM, et al. Identification and assessment of known and novel human papillomaviruses by polymerase chain reaction amplification, restriction fragment length polymorphisms, nucleotide sequence, and phylogenetic algorithms. F Infect Dis 1994;170:1077-85. 
29 Chan PKS, Li WH, Chan MYM, et al. High prevalence of human papillomavirus type 58 in Chinese women with cervical cancer and precancerous lesions. F Med Virol 1999;59: 232-8.

30 Kwok S, Higuchi R. Avoiding false positives with PCR. Nature 1989;339:237-8.

31 Jablonska S, Dabrowski J, Jakubowicz K. Epidermodysplasia verruciformis as a model in studies on the role of papovaviruses in oncogenesis. Cancer Res 1972;32:583-9.

32 Zur Hausen H. Human papillomaviruses and their possible role in squamous cell carcinomas. Curr Top Microbio Immunol 1977;78:1-30.

33 Jarrett WF, Murphy J, O'Neil BW, et al. Virus-induced papillomas of the alimentary tract of cattle. Int $\mathcal{F}$ Cancer 1978; 22:323-8

34 Sood AK. Cigarette smoking and cervical cancer: metaanalysis and critical review of recent studies. Am F Prev Med 1991;7:208-13.

35 Vessey M, Grice D. Carcinoma of the cervix and oral contraceptives: epidemiologic studies. Biomed Pharmacother $1989 ; 43: 157-60$.
36 Brock KE, Berry G, Mock PA, et al. Nutrients in diet and plasma and risk of in situ cervical cancer. $\mathcal{F}$ Natl Cancer Inst plasma and risk

37 Goldstein SC, Byrne JC, Rabson AS. Human cytomegalovirus (HCMV) enhances bovine papilloma virus (BPV) in vitro. F Med Virol 1987;23:157-64.

38 Han CP, Tsao YP, Sun CA, et al. Human papillomavirus, cytomegalovirus and herpes simplex infections for cervical cancer in Taiwan. Cancer Lett 1997;120:217-21.

39 Thompson CH, Rose BR, Elliott PM. Cytomegalovirus and cervical cancer: failure to detect a direct association or an interaction with human papillomaviruses. Gynecol Oncol 1997;54:40-6.

40 Yadav M, Arivananthan M, Kumar S. HHV-6 antigen and viral DNA detected in cervical cells from archived tissue using histochemical staining and hybridization. Clin Diagn Virol 1996; 7:23-33.

41 Wang H, Chen M, Berneman ZN, et al. Detection of human herpesvirus- 6 in paraffin-embedded tissue of cervical cancer by polymerase chain reaction. F Virol Methods 1994; 47:297-305.

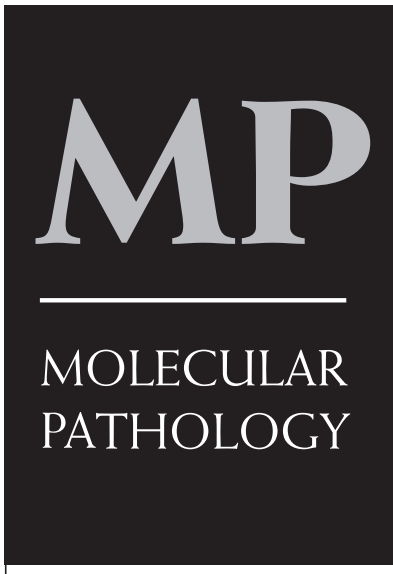

\section{Contents}

\section{December 2000 Vol 53 No 6}

\section{Reviews}

289 Microarray techniques in pathology: tool or toy? A M Snijders, $G$ A Meijer, $R H$ Brakenhoff, $A \mathcal{F} C$ van den Brule, $P \mathcal{F}$ van Diest

295 Cell receptors and cell signalling $I \mathcal{F}$ Uings, $S$ N Farrow

300 Thrombophilia, polymorphisms, and vascular disease TC F Sykes, C Fegan, D Mosquera

\section{Papers}

307 Plasminogen activator system, vascular endothelial growth factor, and colorectal cancer progression $E$ A Baker, $F$ G Bergin, $D$ J Leaper

313 Imbalances of chromosome 17 in medulloblastomas determined by comparative genomic hybridisation and fluorescence in situ hybridisation $\mathcal{F}$ Nicholson, $C$ Wickramasinghe, F Ross, $\mathcal{F}$ Crolla, D Ellison

320 The imprinted $\mathrm{H} 19$ gene is a marker of early recurrence in human bladder carcinoma I Ariel, M Sughayer, Y Fellig, G Pizov, S Ayesh, D Podeh, B A Libdeh, $C$ Levy, $T$ Birman, $M$ L Tykocinski, $N$ de Groot, $A$ Hochberg

324 Prediction of the interacting surfaces in a trimolecular complex formed between the major dust mite allergen Der p 1, a mouse monoclonal anti-Der $\mathrm{p} 1$ antibody, and its anti-idiotype $P B$ Furtado, $R$ Furmonaviciene, $\mathcal{f}$ McElveen, $H F$ Sewell, F Shakib

\section{Short report}

333 A unique junctional palindromic sequence in mitochondrial DNA from a patient with progressive external ophthalmoplegia $T$ Saiwaki, K Shiga, R Fukuyama, Y Tsutsumi, S Fushiki

\section{Miscellanea}

336 Correspondence - Book reviews - Books received $\cdot$ List of assessors

- Christmas message - Annual author index to volume 53 - Annual subject index to volume 53 - Annual contents index to volume 53 